\title{
Amperometric enzyme sensor for the rapid determination of histamine
}

\author{
Ricarda Torre, Estefanía Costa-Rama*, Paula Lopes, Henri P.A. Nouws, Cristina Delerue-Matos** \\ The concentration of histamine, a biogenic amine, in fish is considered a fish spoilage indicator. Therefore, the development \\ of a rapid-response and portable tool that allows its on-site analysis is very interesting since the consumption of high \\ amounts of histamine causes scombroid poisoning. Thus, in this work a simple enzymatic sensor for the determination of \\ histamine, based on a screen-printed carbon electrode and the enzyme diamine oxidase, was developed. The enzyme was \\ immobilized on the electrode surface through a simple cross-linking procedure employing glutaraldehyde and bovine serum \\ albumin. Chronoamperometry was used as the detection technique; the sensor showed a short response time (60 s, $-0.3 \mathrm{~V}$ ) \\ and the measurements were performed by only using $40 \mu \mathrm{L}$ of sample solution. The sensor provides an useful linear range \\ (between 1 and $75 \mathrm{mg} \mathrm{L}^{-1}$ in fish extract), excellent reproducibility (RSD $=2.6 \%$ ) and is reusable for up to 7 measurements. \\ The feasibility of the sensor was tested performing histamine analysis in fish extracts achieving recovery values of $103 \%$.
}

\section{Introduction}

In the last decades, the consumption of fish has increased substantially due to a greater awareness about food habits, with consumers adopting healthier food options. Statistical data show an increase in fish consumption per capita from $9.0 \mathrm{~kg}$ in 1961 to 18.5 $\mathrm{kg}$ in 2011 to $20.2 \mathrm{~kg}$ in $2015^{1}$.

Therefore, the development of simple analytical devices for the assessment of the quality and freshness of fish in a rapid and inexpensive way is an issue of increasing importance. Related to fishery products, histamine is the most widely evaluated parameter and the only amine whose limits are legally established ${ }^{2}$. For fish products, the EU legislation establishes ${ }^{3}$ that the average level of histamine must not exceed $100 \mathrm{mg} \mathrm{kg}^{-1}$ and no sample may contain a concentration higher than $200 \mathrm{mg} \mathrm{kg}^{-1}$. Histamine belongs to a group of compounds known as biogenic amines (including cadaverine, tryptamine, phenylethylamine, ...), which are lowmolecular-weight organic compounds that are formed in foodstuffs mainly by microbial decarboxylation of amino acids ${ }^{4,5}$. It is formed through the decarboxylation of histidine and appears in fish as a result of inappropriate refrigeration or preservation after catching $2,6,7$. Storage at temperatures above $4^{0} C^{8,9}$ is the most important factor contributing to histamine formation, but other parameters such as $\mathrm{pH}$ or salt concentration may also contribute to this ${ }^{10,11}$. This biogenic amine is heat stable, so it is not affected by cooking or prolonged exposure to heat processes and it is also stable after freezing or canning processes ${ }^{12,13}$. It is considered one of the most relevant biogenic amines due to its biological toxicity.

REQUIMTE/LAQV,Instituto Superior de Engenharia do Portdnstituto Politécnico do Porto, Rua Dr. António Bernardino de Almeida 43\#200-072, Porto,Portugal. *e-mail:estefaniarama@graq.isep.ipp.pt; **e-maitmm@isep.ipp.pt Electronic Supplementary Information (ESI) available: 1 PDF file. See DOI: $10.1039 / x 0 x \times 00000 x$
Consumption of fish with high levels of histamine can lead to scombroid fish poisoning (or histamine fish poisoning) and may cause headache, skin problems (flushing) and gastrointestinal problems (diarrhoea, nausea) ${ }^{14,15}$.

Numerous analytical methods have been developed for histamine determination. These methods mainly involve chromatographic techniques ${ }^{5,16}$, for example gas chromatography $(\mathrm{GC})^{17,18}$, highperformance liquid chromatography (HPLC) $)^{19,20}$ and thin layer chromatography ${ }^{21}$. However, these methods possess some limitations, such as the need for expensive instrumentation and highly qualified operators, long analysis times and complex sample pre-treatment (e.g. derivatization). There are also some commercial available ELISA and enzymatic kits for screening of this biogenic amine in food samples ${ }^{22}$.

Electrochemical biosensors are interesting alternatives to conventional methods and commercial kits since they allow short analysis times and low cost analysis, providing adequate sensitivities and user-friendly operating conditions $s^{5,16}$. Moreover, electrochemical sensors based on screen-printed electrodes offer the additional advantage of on-site analysis. This allows the possibility of performing analysis along the entire production chain, from fishing to consumption.

Therefore, in the last years various electrochemical sensors for histamine detection based on screen-printed electrodes have been developed ${ }^{23-26}$, including enzymatic sensors ${ }^{23,24}$. Although electrochemical sensors are characterized by their simplicity, most of the ones previously published require polymers ${ }^{23,27}$, mediators ${ }^{23,28}$, nanomaterials ${ }^{24,27,29,30}$ or two enzymes ${ }^{23,28}$, increasing the overall costs, complexity and construction times. The enzymatic sensor developed in this work stands out for its simplicity; it only requires the enzyme diamine oxidase, which is easily immobilized by crosslinking using very low volumes of glutaraldehyde and bovine serum albumin. The transducer is based on a carbon electrode that senses the products formed by the catalysis of the enzyme to evaluate the 
histamine concentration. Moreover, since the transducer is a screenprinted electrode, a fast-response, user-friendly and portable sensor is obtained. The proposed sensor fulfils some important requirements of Green Analytical Chemistry ${ }^{31}$ such as simplicity, miniaturization, possibility of on-site analysis, use of low reagent/sample amounts and no sample derivatization.

\section{Experimental section}

\section{Reagents and equipment}

Diamine Oxidase from porcine kidney (DAO, $0.11 \mathrm{U} / \mathrm{mg}$ ), bovine serum albumin (BSA), glutaraldehyde (GA), histamine, phenylethylamine, spermine and spermidine were purchased from Sigma Aldrich.

Working solutions of histamine, the other biogenic amines, DAO, BSA and $\mathrm{GA}$ were prepared in $0.1 \mathrm{M}$ phosphate buffer (PB) pH 7.2. Type I ultrapure water (resistivity $=18.2 \mathrm{M} \Omega \mathrm{cm}$ ) was used throughout the work. All chemicals were of analytical reagent grade and were used without further purification.

Electrochemical measurements were performed with a MetrohmAutolab potentiostat/galvanostat (PGSTAT 101) controlled by NOVA software (version 1.10). The screen-printed carbon electrodes (SPCEs, DRP-110) and the connector (DRP-CAC) were supplied by DropSens. The SPCEs consisted of a working electrode (WE, circularshaped, $\mathrm{d}=4 \mathrm{~mm}$ ) and a counter electrode made of carbon ink, and a pseudoreference electrode made of silver ink. This three-electrode cell is printed on a ceramic substrate $(3.4 \mathrm{~cm} \times 1.0 \mathrm{~cm})$.

\section{Enzyme immobilization}

DAO was immobilized on the surface of the WE of the SPCE by a cross-linking process employing BSA and GA. In the optimized procedure, first $2 \mu \mathrm{L}$ of enzyme solution $\left(0.5 \mathrm{mg} \mathrm{m}^{-1}\right)$ and $1 \mu \mathrm{L}$ of BSA solution (3\%) were deposited on the WE. This was followed by adding $1 \mu \mathrm{L}$ of GA solution $(0.5 \%)$ and the electrode was left to dry for 30 min at room temperature. Then, after a washing step with $0.1 \mathrm{M} \mathrm{PB}$ $\mathrm{pH} 7.2$, the biosensor was ready to use.

\section{Electrochemical measurements}

In the measurements, $40 \mu \mathrm{L}$ of the standard/sample solution was placed on the SPCE to cover the three electrodes. All the measurements were performed at room temperature $(22 \pm 1$ 으). For the cyclic voltammetric studies the potential was scanned, at $50 \mathrm{mV}$ $\mathrm{s}^{-1}$, between $-0.8 \mathrm{~V}$ and $+0.8 \mathrm{~V}$ or from $0.0 \mathrm{~V}$ to $-0.6 \mathrm{~V}$. Chronoamperograms were recorded by applying a potential of $-0.3 \mathrm{~V}$ for $60 \mathrm{~s}$, assuring that the current plateau was reached. The average of the last 10 points of the recorded cathodic current was used as the signal for each histamine concentration.

\section{Sample preparation}

For the preparationof the samples(fresh hake and mackerel, purchasedin a local supermarket(Froiz)) a simple procedure indicatedin the protocolof an ELISAtest(R-BiopharmAG) $\quad{ }^{32}$ was followed.In this procedure,5.0 g of the fish sampleweremixed with $20 \mathrm{~mL}$ of distilledwaterusing a vortexmixer. The mixture was then placedin boilingwaterfor $20 \mathrm{~min}$. After cooling, the mixture was centrifugedfor $10 \mathrm{~min}$ at $10000 \mathrm{~g}$. Then, the supernatant was removed andored at $-80 \quad{ }^{\circ} \mathrm{C}$ untiluse.

\section{Results and discussion}

The developed sensor is based on the oxidative deamination of histamine by diamine oxidase to form imidazole acetaldehyde, ammonia and hydrogen peroxide (Fig. 1). Thus, histamine can indirectly be detected through the reduction of the products of the enzymatic reaction (Fig. S1, ESI), whose concentration is directly proportional to the concentration of histamine. For the construction of the sensor, a very easy procedure for enzyme immobilization was employed: simple cross-linking using low amounts of GA and BSA and short drying times. The modification of the SPCE with DAO, DAO/BSA and DA/BSA/GA was characterized by cyclic voltammetry (Fig. S2, ESI). When the SPCE was modified with DAO, an anodic peak was observed at $\approx+0.6 \mathrm{~V}$. This peak remained after the addition of BSA and $\mathrm{GA}$, confirming the immobilization of the enzyme.

Cyclic voltammetry was also used to study the response of the sensor towards histamine. As can been seen in Fig. 2A, the cathodic currents obtained between $-0.6 \mathrm{~V}$ and $0 \mathrm{~V}$ showed a correlation with the histamine concentration: increasing (in absolute value) cathodic currents were clearly observed when the concentration of histamine increased. Chronoamperometry was chosen as the detection technique because it fits perfectly both with SPCEs as well as with portable equipment. A detection potential of $-0.3 \mathrm{~V}$ was chosen since it provided more precise results than the ones obtained at $-0.4 \mathrm{~V}$ (Fig. $2 \mathrm{~B})$ and decreases the interference of other electroactive species that are reduced at more negative potentials. Although at $-0.4 \mathrm{~V}$ higher analytical signals were achieved, the blank signal was also much higher than at $-0.3 \mathrm{~V}$ and the precision was worse.

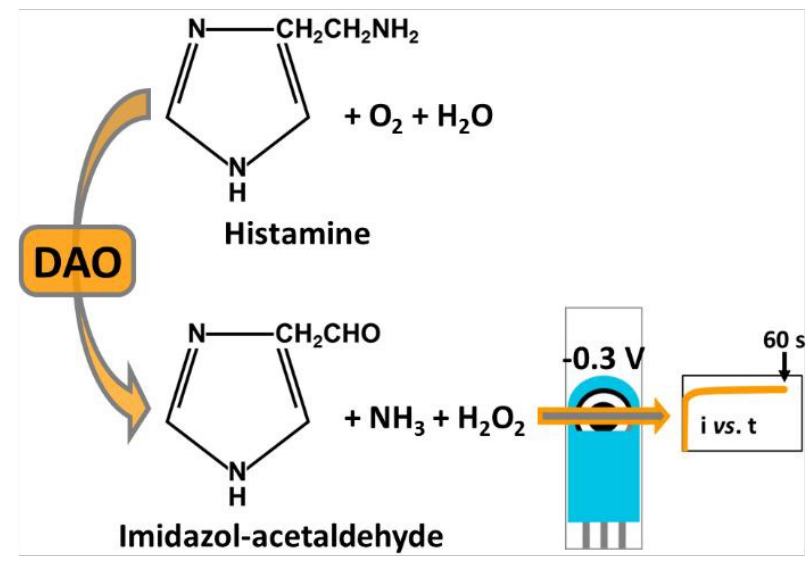

Fig. 1. Schematic representation of the enzymatic and electrochemical reactions at the surface of the electrode.

\section{Immobilization optimization studies}

The $\mathrm{pH}$ is a critical parameter in enzymatic reactions. Thus, along this work, a PB buffer ( $\mathrm{pH}$ 7.2) was used because, according to the supplier, it is the optimum $\mathrm{pH}$ to dissolve the enzyme and it lies within the optimum range $(\mathrm{pH} 6.3-7.4)$ when histamine is the enzymatic substrate. 

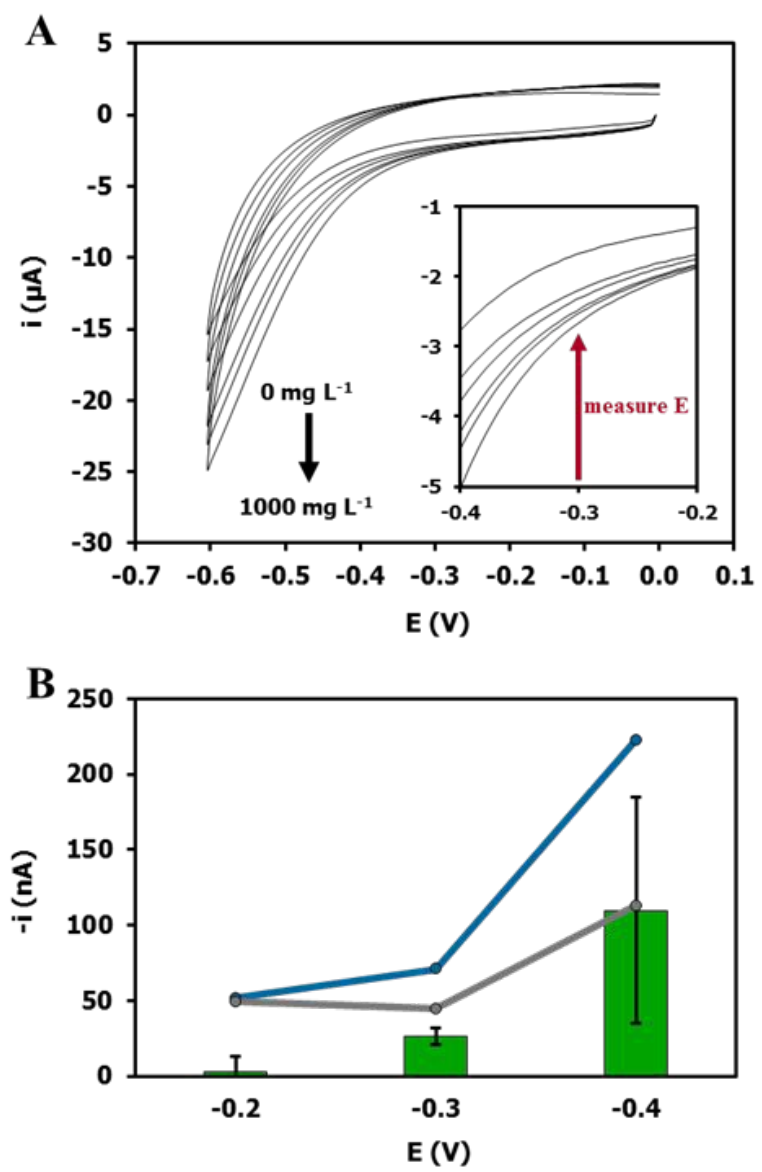

Fig. 2. (A) Cyclic voltammograms recorded with an SPCE modified

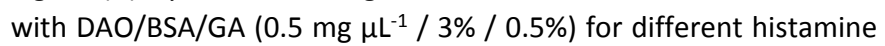
concentrations $\left(0,5,75,250,500\right.$ and $\left.1000 \mathrm{mg} \mathrm{L}^{-1}\right)$, scan rate: $50 \mathrm{mV}$ $\mathrm{s}^{-1}$. Inset: amplification of the cyclic voltammograms between $-0.4 \mathrm{~V}$ and $-0.2 \mathrm{~V}$. (B) Effect of the measuring potential on the blank (grey line), histamine (blue line) and analytical signal ( $\Delta \mathrm{i}$, green bars). Experimental conditions: DAO/BSA/GA $0.5 \mathrm{mg} \mu \mathrm{L}^{-1} / 3 \% / 0.5 \%$ and histamine $25 \mathrm{mg} \mathrm{L}^{-1}$. Average data $\pm S D$ are indicated $(n=3)$.
The concentration of each reagent for the immobilization of DAO by cross-linking with BSA and GA was optimized based on procedures found in the literature ${ }^{33}$. First, the effect of the concentration of BSA on the analytical signal was studied. The use of BSA for cross-linking together with GA allows the reduction of the porosity of the film making it more stable. Low BSA concentrations may result in an insufficient spacing between the enzymes and GA, limiting/blocking the enzymatic activity, which can be minimized with BSA since it is a spacer. On the other hand, high BSA concentrations may also result in a decrease of the enzyme activity ${ }^{34}$. As can be seen in Fig. 3A, the best BSA concentration was $3 \%$. Lower concentrations provided a lower analytical signal and higher concentrations gave a similar analytical signal but a worse precision. The GA concentration had a bigger influence (Fig. 3B) on the response of the sensor. Low concentrations $(0.05 \%$ and $0.1 \%)$ led to slightly higher analytical signals but with a lower precision. For higher GA concentrations, the precision improved but the analytical signals decreased. Therefore, $0.5 \%$ GA was chosen to develop the sensor, compromising between analytical signal and precision. Finally, the DAO concentration was studied using $0.05,0.10,0.25$ and $0.50 \mathrm{mg} \mathrm{hL}^{-1}$ solutions. Higher concentrations were not used because of the solubility of the enzyme. Fig. $3 \mathrm{C}$ shows that the highest DAO concentration resulted in a better analytical signal and precision. Therefore, $0.50 \mathrm{mg}^{-1}$ was chosen to construct the sensor.

\section{Analytical characteristics of the histamine sensor}

To establish the performance characteristics of the sensor, histamine concentrations between 1 and $500 \mathrm{mg} \mathrm{L}^{-1}$ were analysed (Fig. 4A and Fig. S3, ESI). The current difference between the ones obtained for different histamine concentrations and the blank $(\Delta|\mathrm{i}|)$ showed a linear relationship for histamine concentrations between 1 and 100 $\mathrm{mg} \mathrm{L}^{-1}$ (Fig. 4A) with a sensitivity of $0.33 \mathrm{nA} \mathrm{L} \mathrm{mg}{ }^{-1}$ and a correlation coefficient of 0.9991 . The limit of detection, calculated as 3 times the standard deviation of the blank signal divided by the slope, was 0.94 $\mathrm{mg} \mathrm{L}^{-1}$. These and additional figures of merit are indicated in Table $\mathrm{S} 1$. The coefficient of variation of the method $(\mathrm{V} \times \mathrm{O})$ was lower than $5 \%$, demonstrating the good precision of the method for the analysis of histamine.
A

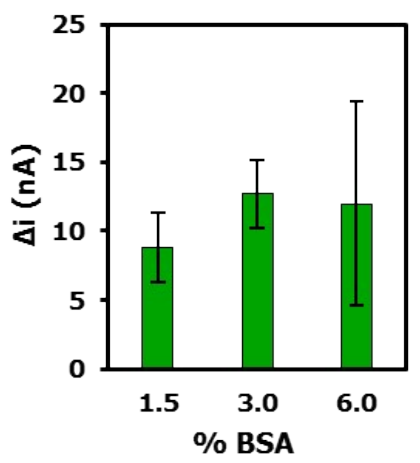

B

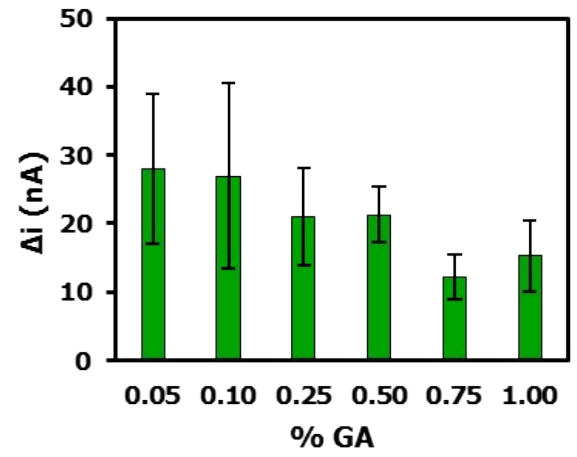

C

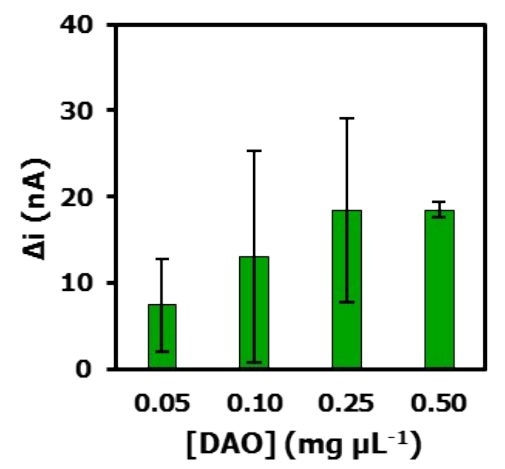

Fig. 3. Effect of the concentration of (A) BSA, (B) GA and (C) DAO on the analytical signal ( $\triangle \mathrm{i}$ ) for $25 \mathrm{mg} \mathrm{L}^{-1}$ histamine. Experimental conditions: (A) DAO/GA, $0.5 \mathrm{mg} \mathrm{\mu L}^{-1} / 0.1 \%$; (B) DAO/BSA, $0.5 \mathrm{mg} \mathrm{\mu L}^{-1} / 3 \%$; (C) BSA/GA, 3\%/0.5\%. Average data \pm SD are indicated $(n=3)$. 
Table 1. Comparison of analytical properties of some electrochemical methods for histamine detection.

\begin{tabular}{|c|c|c|c|c|c|c|}
\hline Transducer & Construction & Detection & $\begin{array}{l}\text { Sensitivity } \\
\left(\mathrm{nA} L \mathrm{mg}^{-1} \text { ) }\right.\end{array}$ & $\begin{array}{l}\text { Concentration } \\
\text { range }\left(\mathrm{mg} \mathrm{L}^{-1}\right)\end{array}$ & $\begin{array}{l}\text { LOD } \\
\left(\mathrm{mg} \mathrm{L}^{-1}\right)\end{array}$ & Ref. \\
\hline SPCE & $\mathrm{DAO} / \mathrm{BSA} / \mathrm{GA}$ & Chronoamp. & 3.8 & $1-75$ & 0.5 & This work \\
\hline SPCE & $\begin{array}{l}\mathrm{DAO} / \mathrm{HRP} \text { immobilized into a } \\
\text { /polysulfone/CNTs/ferrocene membrane }\end{array}$ & Amperometry & 157 & $0.033-2.22$ & 0.018 & 23 \\
\hline SPCE & $\begin{array}{l}\text { DAO/Platinum } \\
\text { nanoparticles/graphene/chitosan }\end{array}$ & Amperometry & 568 & $0.01-33.34$ & 0.0028 & 24 \\
\hline SPCE & Rhenium (IV) oxide & Amperometry & 19 & $0.5-10$ & 0.2 & 25 \\
\hline SPCE & Nafion/Cu $\left(\mathrm{PO}_{4}\right)_{2}$ & Amperometry & 13.1 & $5-100$ & 3 & 26 \\
\hline SPCE (as WE) & DAO/PhotoHema & \multirow{2}{*}{ Amperometry } & 5.56 & $5-60$ & 0.65 & \multirow{2}{*}{35} \\
\hline SPCE & $\mathrm{Fe}(\mathrm{CN})_{6}^{4-/ D A O / P h o t o H e m a ~}$ & & 5.31 & $10-80$ & - & \\
\hline $\begin{array}{l}\text { Platinum } \\
\text { electrode }\end{array}$ & Copper layer & Amperometry & 109 & $0.1-83.4$ & 0.03 & 36 \\
\hline GCE & MWCNTs/p-(AHNSA) & DPV & 6981 & $0.01-11.11$ & 0.0084 & 29 \\
\hline $\begin{array}{l}\text { Carbon paste } \\
\text { electrode }\end{array}$ & SWCNTS & DPV & $1511 ; 1062$ & $\begin{array}{l}0.5-20 \\
20-80\end{array}$ & 0.14 & 30 \\
\hline GCE & $\begin{array}{l}\text { Polystyrene-graphene oxide } \\
\text { nanocomposite }\end{array}$ & DPV & 4618 & $0.011-0.333$ & 0.003 & 37 \\
\hline $\begin{array}{l}\text { Edge plane } \\
\text { pyrolytic graphite } \\
\text { electrode }\end{array}$ & GNRs-AgNPs & SWV & $1421 ; 747$ & $\begin{array}{l}0.1-5.6 \\
6.7-55.6\end{array}$ & 0.0054 & 38 \\
\hline GCE & Lignin & SWV & 8457 & $0.56-22.2$ & 0.03 & 39 \\
\hline GCE & Thin film of mercury & Potentiometry & - & $\begin{array}{l}1.5-10.5 \\
5-30 ; 20-90\end{array}$ & 1.31 & 40 \\
\hline $\begin{array}{l}\text { lon-selective } \\
\text { electrode }\end{array}$ & MIP-nanoparticles membrane & Potentiometry & - & $0.11-1111.5$ & 0.12 & 41 \\
\hline
\end{tabular}

Chronoamp.: Chronoamperometry; HRP: horseradish peroxidase; CNTs: carbon nanotubes; GCE: glassy carbon electrode; CV: cyclic voltammetry; MWCNTs: multiwalled carbon nanotubes; p-(AHNSA): poly(4-amino-3-hydroxynaphthalene sulfonic acid); DPV: differential pulse voltammetric; SWCNTs: single-walled carbon nanotubes; PhotoHema: photocured poly(2-hydroxyethyl methacrylate); MIP: molecularly imprinted polymer; SWV: square wave voltammetry; GNRs: graphene nanoribbons; AgNPs: silver nanoparticles.

The reproducibility was also evaluated using 5 different equivalently prepared sensors: RSDs of $2.6 \%$ and $2.1 \%$ were obtained for 1 and 25 $\mathrm{mg} \mathrm{L}^{-1}$ histamine, respectively. It should also be noted that the same sensor can be used for several measurements; Fig. 4A presents the average of three calibration curves using three different sensors. In order to evaluate the precision of the sensor when it is reused, 7 measurements of a $25-\mathrm{mg} \mathrm{L}^{-1}$ histamine solution were performed with three different sensors, obtaining an RSD of $7.7 \%$ (for the 21 measurements).

\section{Interferences studies}

To evaluate the effects of some potentially interfering substances in fish on the analysis of histamine, the biosensor's response towards some biogenic amines, such as phenylethylamine, spermidine and spermine, was studied. The effect of these biogenic amines was assessed by comparison of the analytical signal $(\Delta|\mathrm{i}|)$ obtained for 10 and $25 \mathrm{mg} \mathrm{L}^{-1}$ histamine solution vs. the signal obtained for solutions of the same concentration of the biogenic amines (Fig. 4B). It was observed that spermidine was not an important interfering substance since no signal was observed for $10 \mathrm{mg} \mathrm{L}^{-1}$, and for $25 \mathrm{mg}$
$\mathrm{L}^{-1}$ the signal represented only $12 \%$ of the histamine response. For spermine, the response was higher but the same for both $10 \mathrm{mg} \mathrm{L}^{-1}$ and $25 \mathrm{mg} \mathrm{L}^{-1}$. In the case of phenylethylamine, a very low response was obtained for $10 \mathrm{mg} \mathrm{L}^{-1}$. For $25 \mathrm{mg} \mathrm{L}^{-1}$ the response increased but was less than half the response for histamine. These interferences are due to the fact that DAO is a non-selective enzyme; nevertheless, it is a widely employed enzyme for developing analytical methods for histamine detection $23,24,27$. It is important to take into account that, when fish is stored at high temperatures or during long times, the levels of the other biogenic amines increase more slowly than histamine $e^{6,42}$, therefore, reducing their possible interference effects.

\section{Real sample analysis}

Since the fish extract showed significant matrix effects, a calibration plot was constructed in spiked hake extracts. Hake was chosen to perform the calibration since it is a histidine-poor fish and therefore, it undergoes a very slow formation of histamine ${ }^{7,43}$. Hake extracts were spiked with different histamine concentrations and were analysed with the developed sensor. A linear relationship between the current intensity and the histamine concentration was founded 
from 1 to $75 \mathrm{mg} \mathrm{L}^{-1}$, according to the equation $|\mathrm{i}|(\mathrm{nA})=3.8$ [Histamine] $\left(\mathrm{mg} \mathrm{L}^{-1}\right)+999.3, \mathrm{R}=0.998$. The LOD, calculated as before, was $0.5 \mathrm{mg} \mathrm{L}^{-1}$. This demonstrated that the sensor can detect histamine in real fish extracts. Although the linear range is narrower when fish matrix is used than when histamine solutions are prepared in buffer $\left(1-75\right.$ vs. $\left.1-100 \mathrm{mg} \mathrm{L}^{-1}\right)$, the sensitivity is much better (3.8

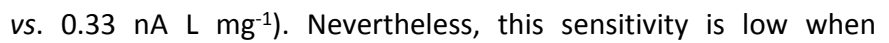
compared to other previously reported sensors (see Table 1). However, and despite the sensor's simplicity, it showed a linear range and an LOD comparable, or in some cases better, than other sensors that involve much more laborious and expensive procedures for their construction, such as a bi-enzymatic system ${ }^{23}$, polymers for enzyme immobilization 27,35 or nanomaterials ${ }^{26,27,30}$ (Table 1).

This calibration plot was employed to perform recovery tests using hake and mackerel extracts in order to demonstrate the potential of this sensor for histamine detection in different fish species. Spikes of 20 (for mackerel extract) and $40 \mathrm{mg} \mathrm{L}^{-1}$ (for hake extract) were performed obtaining recoveries of $103.0 \%$ and $103.5 \%$, respectively (Table 2). These values showed that this simple sensor could be applied to the determination of histamine in fish samples.
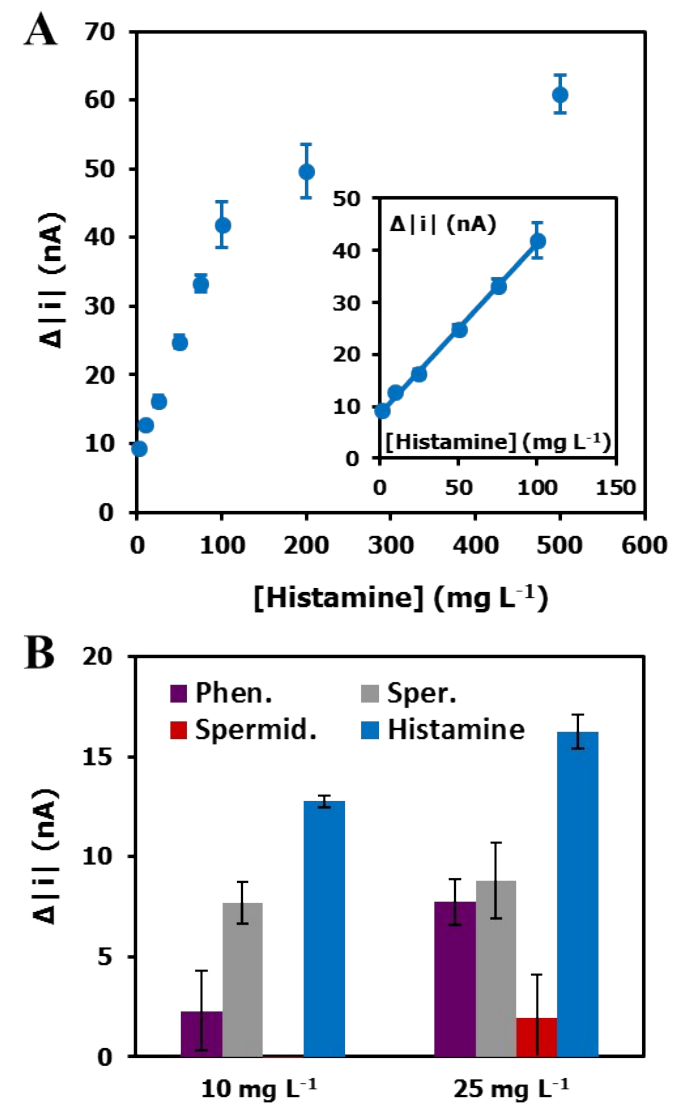

Fig. 4. (A) $\Delta|\mathrm{i}|$ values obtained for different histamine concentrations using the developed sensor (chronoamperometry at $-0.3 \mathrm{~V}$ for $60 \mathrm{~s}$; average values of three calibration curves performed with three different sensors). Inset: linear range of the calibration curve. (B) $\Delta|\mathrm{i}|$ values obtained with the developed sensor (chronoamperometry at $-0.3 \mathrm{~V}$ for $60 \mathrm{~s}$ ) for 10 and $25 \mathrm{mg} \mathrm{L}^{-1}$ of histamine and three potential interferents: phenylethylamine, spermine and spermidine. Average data \pm SD are indicated $(n=3)$.
Table 2. Recovery test of the proposed biosensor for the analysis of histamine in fish extracts (average data $\pm S D$ are indicated $(n=3)$ ).

\begin{tabular}{llll}
\hline Fish & $\begin{array}{l}\text { Histamine } \\
\text { added }\left(\mathrm{mg} \mathrm{L}^{-1}\right)\end{array}$ & $\begin{array}{l}\text { Found value } \\
\left(\mathrm{mg} \mathrm{L}^{-1}\right)\end{array}$ & Recovery (\%) \\
\hline Mackerel & 20 & $20.6 \pm 1.1$ & $103.0 \pm 5.4$ \\
Hake & 40 & $41.4 \pm 2.1$ & $103.5 \pm 5.2$ \\
\hline
\end{tabular}

\section{Conclusions}

A simple enzymatic sensor for histamine analysis based on SPCEs was developed employing diamine oxidase, which was immobilized by cross-linking using very low amounts of glutaraldehyde and bovine serum albumin. This simple and low-cost sensor allows the determination of histamine in a wide concentration range, showing high reproducibility and short response times. Its feasibility to determine histamine in extracts of different fish species was also demonstrated.

This sensor was developed in accordance with the current trends in green and analytical chemistry: simple, miniaturized and portable devices that require low reagent and sample volumes, producing low amounts of waste. Thus, the enzymatic sensor developed in this work fulfils these requirements and moreover, since it is based on an SPCE, it can be combined with portable and ready-to-use devices allowing the on-site histamine analysis along the whole fish production chain.

\section{Acknowledgements}

The authors are grateful for the financial support from FCT/MEC through national funds and co-financed by FEDER, under the Partnership Agreement PT2020 through the project UID/ QUI/50006/2013. The authors would also like to thank the EU and FCT for funding through the projects: FishBioSensing - Portable electrochemical (bio)sensing devices for safety and quality assessment of fishery products (02/SAICT/2016, POCI-01-0145FEDER-023817) and FOODnanoHEALTH - Qualidade e Segurança Alimentar - uma abordagem (nano)tecnológica (Portugal2020, Norte-01-0145-FEDER-000011).

\section{References}

1

FAO (Food and Agriculture Organization of the United Nations), The state of world fisheries and aquaculture. Meeting the sustentainable development goals, 2018. L. Prester, Food Addit. Contam. Part A, 2011, 28, 15471560. Off. J. Eur. Union. Comm. Regul. No 2073/2005 15 Novemb. 2005 Microbiol. criteria Foodst., 2005, L322, 1-19. K. B. Biji, C. N. Ravishankar, R. Venkateswarlu, C. O. Mohan and T. K. S. Gopal, J. Food Sci. Technol., 2016, 53, 22102218.

5 M. Papageorgiou, D. Lambropoulou, C. Morrison, E. Kłodzińska, J. Namieśnik and J. Płotka-Wasylka, TrAC Trends Anal. Chem., 2018, 98, 128-142.

6 P. Visciano, M. Schirone, R. Tofalo and G. Suzzi, Front. Microbiol., 2012, 3, 1-10. 
L. Prester, J. Macan, V. M. Varnai, T. Orct, J. Vukusic and D. Kipčić, Food Addit. Contam. Part A, 2009, 26, 355-362. Y.-H. Tsai, S.-C. Chang, H.-F. Kung, C.-I. Wei and D.-F. Hwang, J. Food Prot., 2005, 68, 1690-1695. C. C. G. Silva, D. J. B. Da Ponte and M. L. N. E. Dapkevicius, J. Food Sci., 1998, 63, 644-647. K. Bjornsdottir-Butler, D. P. Green, G. E. Bolton and P. D. McClellan-Green, J. Food Sci., 2015, 80, M1253-M1258. H.-F. Kung, C.-Y. Huang, C.-M. Lin, L.-H. Liaw, Y.-C. Lee and Y.-H. Tsai, J. Food Drug Anal., 2015, 23, 335-342.

A. Naila, S. Flint, G. Fletcher, P. Bremer and G. Meerdink, J. Food Sci., 2010, 75, R139-R150. P. Visciano, M. Schirone, R. Tofalo and G. Suzzi, Front. Microbiol., 2014, 5, 1-3.

C. Feng, S. Teuber and M. E. Gershwin, Clin. Rev. Allergy Immunol., 2016, 50, 64-69.

15 J. M. Hungerford, Toxicon, 2010, 56, 231-243.

16 J. L. Ordóñez, A. M. Troncoso, M. D. C. García-Parrilla and R. M. Callejón, Anal. Chim. Acta, 2016, 939, 10-25.

S. C. Cunha, M. A. Faria and J. O. Fernandes, J. Agric. Food Chem., 2011, 59, 8742-8753.

C. Almeida, J. O. Fernandes and S. C. Cunha, Food Control, 2012, 25, 380-388. Y. Q. Wang, D. Q. Ye, B. Q. Zhu, G. F. Wu and C. Q. Duan, Food Chem., 2014, 163, 6-15.

C. A. Lázaro, C. A. Conte-Júnior, F. L. Cunha, E. T. Mársico, S. B. Mano and R. M. Franco, Food Anal. Methods, 2013, 6, 1024-1032.

A. Romano, H. Klebanowski, S. La Guerche, L. Beneduce, G. Spano, M. L. Murat and P. Lucas, Food Chem., 2012, 135, 1392-1396.

S. Köse, N. Kaklikkaya, S. Koral, B. Tufan, K. C. Buruk and F. Aydin, Food Chem., 2011, 125, 1490-1497.

S. Pérez, J. Bartrolí and E. Fàbregas, Food Chem., 2013, 141, 4066-4072.

I. M. Apetrei and C. Apetrei, Sensors, 2016, 16, 1-15.

A. Veseli, M. Vasjari, T. Arbneshi, A. Hajrizi, L. Švorc, A. Samphao and K. Kalcher, Sensors Actuators, B Chem., 2016, 228, 774-781.

M.-Y. Lee, C.-C. Wu, M. I. Sari and Y. Hsieh, Electrochim. Acta, 2018, 283, 772-779.

M. B. Gumpu, N. Nesakumar, S. Sethuraman, U. M. Krishnan and J. B. B. Rayappan, Sensors Actuators B. Chem., 2014, 199, 330-338.

S. Leonardo and M. Campàs, Microchim. Acta, 2016, 183, 1881-1890. A. Geto, M. Tessema and S. Admassie, Synth. Met., 2014, 191, 135-140. Z. S. Stojanović, E. Mehmeti, K. Kalcher, V. Guzsvány and D. M. Stanković, Food Anal. Methods, 2016, 9, 2701-2710.

A. Gałuszka, Z. Migaszewski and J. Namieśnik, TrAC - Trends Anal. Chem., 2013, 50, 78-84. https://food.r-biopharm.com/products/ridascreenhistamin-enzymatic-2/ (Last accessed January 2019).

W. Henao-Escobar, O. Domínguez-Renedo, M. Asunción
S. B. Adeloju and A. T. Lawal, Anal. Chim. Acta, 2011, 691, 89-94.

C. M. Keow, F. A. Bakar, A. B. Salleh, L. Y. Heng, R. Wagiran and S. Siddiquee, Int. J. Electrochem. Sci., 2012, 7, 47024715.

Y. Lin, C. Chen and M. S. Lin, Sensors Actuators B. Chem., 2018, 255, 2838-2843.

L. Saghatforoush, M. Hasanzadeh and N. Shadjou, Chinese Chem. Lett., 2014, 25, 655-658.

N. Kumar and R. N. Goyal, Sensors Actuators B. Chem., 2018, 268, 383-391.

H. Degefu, M. Amare, M. Tessema and S. Admassie, Electrochim. Acta, 2014, 121, 307-314.

J. Švarc-Gajić and Z. Stojanović, Food Chem., 2011, 124, 1172-1176.

I. Basozabal, A. Guerreiro, A. Gomez-Caballero, M. Aranzazu Goicolea and R. J. Barrio, Biosens. Bioelectron., 2014, 58, 138-144.

2 M. T. Veciana-Nogués, A. Mariné-Font and M. C. VidalCarou, J. Agric. Food Chem., 1997, 45, 2036-2041. C. Ruiz-Capillas and A. Moral, J. Food Sci., 2001, 66, 10301032. Alonso-Lomillo and M. Julia Arcos-Martínez, Talanta, 2013, 117, 405-411. 